\title{
Posgrado: 25 años de excelencia académica
}

\author{
Postgraduate education: 25 years of academic excellence
}

La "Fuerza Innovadora” que inspiró a los fundadores de la Facultad de Estomatología de la Universidad Peruana Cayetano Heredia, marcó no solo la formación de un sólido programa de pregrado, con un currículo integrado y una enseñanza novedosa, sino también el crecimiento y la consolidación de la educación en estomatología mediante el desarrollo de programas escolarizados a nivel de posgrado en nuestra casa de estudios.

En las décadas de 1970 y 1980, la tarea se centró en lograr un pregrado de excelencia, entretanto la formación a nivel de posgrado paralelamente se dirigió a la capacitación a través de cursos de educación continua bajo diversas modalidades, siempre con la inquietud de formar especialistas.

En 1990, cuando se tomó la decisión trascendental de poner en marcha los programas escolarizados de posgrado, se inició una gesta que ha ido creciendo y afianzándose sostenidamente de manera importante a lo largo de los últimos veinticinco años.

Los programas de segunda especialidad se iniciaron con las áreas clínicas de Cirugía Oral y Maxilofacial, Ortodoncia y Rehabilitación Oral. A ellos fueron sumándose los programas de Endodoncia, Patología y Medicina Oral, Odontología Pediátrica, Periodoncia, Radiología Oral; este último primero en la modalidad presencial y luego en la virtual; posteriormente Estomatología de Pacientes Especiales, Odontología Restauradora y Estética e Implantología Oral Integral. Finalmente, en los últimos años se crearon los programas en áreas que complementan e integran la formación odontológica, como: Odontología Legal y Forense, Administración y Gestión en Estomatología, Auditoría Odontológica y Calidad Asistencia y Salud Pública Estomatológica.

De ese modo; sobre la base de un exigente entrenamiento, apoyado por una óptima infraestructura en las sedes de San Martín y Salaverry con tecnología de punta, así como de una excelente plana docente de amplia trayectoria y reconocimiento internacional; hemos logrado formar especialistas altamente calificados que son solicitados no solamente para la atención especializada en la práctica pública o privada, brindando mejores niveles de atención bucal a la población, sino además son requeridos como docentes en diversas universidades del país y del extranjero.

De otra parte, a través de nuestros programas de diplomado en las diversas ramas de la estomatología, tanto en el área clínica como en la de gestión y administración en salud, brindamos una capacitación que más allá de complementar conocimientos, adquirir nuevas destrezas y disciplina académica, otorga sólidas bases teóricas, prácticas y clínicas a nuestros egresados, permitiéndoles así inclinarse progresivamente con certidumbre por una determinada área de nuestra profesión: un importante paso en su larga travesía formativa. Por otro lado, un segundo grupo igualmente importante sigue este tipo de programas en función de afianzar lo aprendido en el 
pregrado, lo cual redundará en que su desempeño profesional se sustente en una mayor seguridad y confianza. Por su parte, un tercer grupo de profesionales que ya han culminado determinados estudios de postgrado, pueden ampliar sus perspectivas incursionando mediante un diplomado en disciplinas complementarias con las que ya tienen formación y experiencia.

Otra de las tareas y compromisos educativos desarrollados en la Unidad de Posgrado es la capacitación constantea través de nuestro programa de educación continua: diverso, variado y con múltiples modalidades, vía permanente de capacitación y actualización en todas las áreas, cuya constante demanda se da por el rápido avance tecnológico de nuestra profesión y por el cada vez mayor número de egresados provenientes de una cantidad creciente de facultades y escuelas de odontología en todo el país.

Finalmente nuestros programas de Maestría y Doctorado, que a través de los años han ido consolidándose con el desarrollo de líneas de investigación, aseguran la formación de un profesional idóneo en docencia e investigación, con capacidad de realizar propuestas para mejorar la calidad de vida de la población y resolver problemas en la profesión.

Al término de estos veinticinco años la unidad de posgrado cuenta con 2064 egresados de nuestros programas de diplomado, segunda especialidad, maestría y doctorado, en los que hasta 2015 se produjeron 299 tesis, muchas de ellas publicadas en este órgano de difusión de nuestra facultad.

Actualmente ofrecemos veinticinco programas académicos entre diplomados y segundas especialidades, que involucran el área clínica y el área de gestión; así como doce programas de maestría en estomatología, de especialidad y de doctorado, lo que nos ha permitido sobresalir y distinguirnos como una institución referente en nuestro país y en América Latina.

Aún quedan muchos retos por resolver, entre ellos una apropiada implementación del Residentado Odontológico. Precisamente los desafíos nos motivan a mantener nuestro compromiso institucional de brindar a la sociedad, profesionales altamente calificados para un mejor nivel de atención y mayor cobertura, en beneficio de la sociedad, misión propia de una institución que honra su responsabilidad de formar y capacitar con solvencia profesionales especialistas, maestrandos y doctorandos.

Janett Mas López ${ }^{1, a}$ 